\title{
EFFICACY OF ROCURONIUM PRIMING VERSUS PRE-TREATMENT WITH MAGNESIUM SULPHATE DURING ROCURONIUM INTUBATION FOR ELECTIVE GENERAL SURGICAL CASES. A RANDOMISED, PROSPECTIVE, DOUBLE-BLINDED CONTROLLED TRIAL
}

\author{
Gudala Prasanna Kumar1, Kamadi Lakshmana Rao ${ }^{2}$
}

${ }^{1}$ Associate Professor, Department of Anaesthesiology, Dr. NTR University of Health Sciences, Vijayawada, Andhra Pradesh, India.

${ }^{2}$ Assistant Professor, Department of Anaesthesiology, Dr. NTR University of Health Sciences, Vijayawada, Andhra Pradesh, India.

\section{BACKGROUND}

ABSTRACT

Rocuronium is a non-depolarising muscle relaxant, which has the ability to produce good-to-excellent intubating conditions within 60 - 90 seconds without side effects, but still Succinylcholine only has the advantage of producing excellent intubating conditions in less than 60 seconds. Application of priming principle, pre-treatment with agents like magnesium, sevoflurane, lignocaine, ephedrine etc.; in various randomised clinical trials and proved to be of varying efficacy in reducing the time of onset of rocuronium blockade.

In this study, the aim is to determine whether priming dose of rocuronium versus pre-treatment with magnesium sulphate 3 minutes prior to intubating dose of rocuronium produces rapid onset of muscle relaxation and optimal intubating conditions.

\section{MATERIALS AND METHODS}

This is a randomised, double-blinded controlled trial. After Institutional Ethical Committee approval and written informed consent, 75 patients belonging to both genders were randomly taken for this double-blinded, prospective and placebo-controlled study. Patients belonging to ASA I/II, both sexes, aged between 18 - 60 yrs., weighing 40 - 80 kgs, Mallampati grading I/II, posted for elective general surgical cases were taken up for this study. Patients were randomly divided into three groups of 25 each. Group RR: Patients were assigned to receive $0.06 \mathrm{mg} / \mathrm{kg}$ of IV rocuronium as priming dose in a volume of $3 \mathrm{~mL} 3 \mathrm{minutes}$ prior to intubating dose of rocuronium $0.54 \mathrm{mg} / \mathrm{kg}$. Group RM: Patients were assigned to receive $30 \mathrm{mg} / \mathrm{kg}$ of IV magnesium sulphate in $100 \mathrm{~mL}$ of normal saline 10 minutes prior to induction of general anaesthesia. Group RC: Patients were assigned to receive $100 \mathrm{~mL}$ of normal saline 10 minutes before induction and $3 \mathrm{~mL}$ of normal saline 3 minutes before intubating dose of rocuronium $0.6 \mathrm{mg} / \mathrm{kg}$ IV to ensure blinding. The following parameters were assessed during and after intubation and at specific time points following intubation. Haemodynamic parameters were assessed at baseline, $1 \mathrm{~min}, 3 \mathrm{mins}$ and $5 \mathrm{mins}$ following intubation, mean onset time of muscle relaxation, mean time taken for laryngoscopy and intubation and intubating conditions were assessed.

\section{RESULTS}

The mean onset time to muscle relaxation was significantly less in the rocuronium priming group and rocuronium with magnesium group when compared to the control group, $\mathrm{p}<0.001$, statistically significant. 92\% (23) of cases in RR group reported excellent intubating conditions, $84 \%$ (21) of cases in RM group reported excellent intubating conditions and only $40 \%$ (10) of cases in the control group reported excellent intubating conditions.

\section{CONCLUSION}

Interventions like rocuronium priming and/or pre-treatment with magnesium sulphate significantly accelerated the onset time to intubating dose of rocuronium when compared to control group.

\section{KEY WORDS}

Magnesium Sulphate, Rocuronium, Sevoflurane, Intubating Conditions, Haemodynamic Parameters.

HOW TO CITE THIS ARTICLE: Kumar GP, Rao KL. Efficacy of rocuronium priming versus pre-treatment with magnesium sulphate during rocuronium intubation for elective general surgical cases, a randomised, prospective, double-blinded controlled trial. J. Evolution Med. Dent. Sci. 2018;7(35):3888-3893, DOI: $10.14260 /$ jemds/2018/870

\section{BACKGROUND}

Succinylcholine is the gold standard muscle relaxant for tracheal intubation during general anaesthesia, because of its rapid onset and short duration of action. ${ }^{1}$

'Financial or Other Competing Interest': None. Submission 16-07-2018, Peer Review 09-08-2018,

Acceptance 16-08-2018, Published 27-08-2018.

Corresponding Author:

Dr. Kamadi Lakshmana Rao,

D/No. 31-3-4, Bongaralavari Street,

Suryanarayanapuram,

Kaklianda-533001, East Godavari District,

Andhra Pradesh, India.

E-mail:laxmankamadi@gmail.com

DOI: $10.14260 /$ jemds $/ 2018 / 870$

\section{(c) $(\mathrm{P})($}

However, because of the side effects associated with Succinylcholine, Rocuronium has become an alternative agent for tracheal intubation, especially in situations of anticipated difficult airway and rapid sequence intubation according to recent clinical trials. ${ }^{2,3}$ Rocuronium is a non-depolarising muscle relaxant, which has the ability to produce good-toexcellent intubating conditions within 60 - 90 seconds without side effects, but still Succinylcholine only has the advantage of producing excellent intubating conditions in less than 60 seconds. 4

Several pharmacological interventions have been tried to hasten the onset of rocuronium induced muscle blockade namely application of priming principle, pre-treatment with agents like magnesium, sevoflurane, lignocaine, ephedrine etc.; in various randomised clinical trials and proved to be of varying efficacy in reducing the time of onset of rocuronium 
blockade.5,6 Priming principle suggests that a small subparalysing dose of non-depolarising muscle relaxant administered few minutes (2 - 3 mins $)$ prior to administration of intubating dose of non-depolarising muscle relaxant accelerates the onset of muscle blockade by $30-60$ seconds. ${ }^{7}$

Hence, in this study the aim is to determine whether priming dose of rocuronium versus pre-treatment with magnesium sulphate 3 minutes prior to intubating dose of rocuronium produces rapid onset of muscle relaxation and optimal intubating conditions.

\section{MATERIALS AND METHODS}

This is a randomised, double-blinded controlled trial. After Institutional Ethical Committee approval and written informed consent, 75 patients belonging to both genders were randomly taken for this study for convenience. Randomisation was done using computer generated random numbers. This study was conducted in a tertiary care hospital during the period between March 2016 and November 2016. Patients belonging to ASA I/II, both sexes, aged between 18 60 yrs., weighing 40 - $80 \mathrm{kgs}$, Mallampati grading I/II, posted for elective general surgical cases were taken up for this study.

A total of 75 patients who met the inclusion criteria were included in the study. Patients were randomly divided into groups in a double-blind manner. In the operating room, patients were randomised by sealed envelope method (wherein externally computer-generated numbers were used) to the groups. The randomisation code allotted to the patients was kept separately and investigators were blinded to it until the study was completed.

\section{Exclusion Criteria}

- Pregnancy.

- Neurological disorders.

- Neuromuscular disease.

- Chronic use of calcium channel blockers.

- Patient refusal.

Patients were randomly divided into Three Groups of 25 each-

\section{Group RR}

Patients were assigned to receive $0.06 \mathrm{mg} / \mathrm{kg}$ of IV rocuronium as priming dose in a volume of $3 \mathrm{~mL} 3$ minutes prior to intubating dose of rocuronium $0.54 \mathrm{mg} / \mathrm{kg}$. Ten minutes prior to induction, $100 \mathrm{~mL}$ normal saline was administered as a placebo to ensure blinding.

\section{Group RM}

Patients were assigned to receive $30 \mathrm{mg} / \mathrm{kg}$ of IV magnesium sulphate in $100 \mathrm{~mL}$ of normal saline 10 minutes prior to induction of general anaesthesia. Three minutes prior to intubating dose of rocuronium $0.6 \mathrm{mg} / \mathrm{kg} \mathrm{IV}, 3 \mathrm{~mL}$ of normal saline was administered to ensure blinding.

\section{Group RC}

Patients were assigned to receive $100 \mathrm{~mL}$ of normal saline 10 minutes before induction and $3 \mathrm{~mL}$ of normal saline 3 minutes before intubating dose of rocuronium $0.6 \mathrm{mg} / \mathrm{kg} \mathrm{IV}$ to ensure blinding.
Standard GA regimen was administered in all the three groups with midazolam $0.03 \mathrm{mg} / \mathrm{kg}$ IV for premedication fentanyl $2 \mathrm{ug} / \mathrm{kg}$ IV, Propofol $2-2.5 \mathrm{mg} / \mathrm{kg}$ IV for induction and rocuronium $0.6 \mathrm{mg} / \mathrm{kg}$ for intubation. The study drugs were administered in respective groups according to group allocation. 18-G IV cannula was secured in the preanaesthetic room and all patients were shifted to operating room and applied monitors for HR, NIBP, ECG and SpO2. Baseline parameters like HR, SBP, MAP, DBP, RR and $\mathrm{SpO}_{2}$ were recorded. The study drugs were provided to the operating room in sealed envelopes just before administration to ensure blinding. The principle investigator is a senior anaesthesiologist who was aware of the group allocation and who prepared and loaded the study drugs accordingly. Intubation was done by a senior resident who was unaware of group allocation and study drugs and who was not involved in the observation and collection of data. Observation of outcomes and collection of data was done by another anaesthesiologist who was also unaware of group allocation.

The following Parameters were assessed during and after Intubation and at Specific Time Points following Intubation

- Haemodynamic parameters were assessed at baseline, 1 min, 3 mins and 5 mins following intubation.

- Mean onset time of muscle relaxation, defined as time since administration of intubating dose of rocuronium to adequate jaw relaxation.

- Mean time taken for laryngoscopy and intubation, defined as the time since the start of laryngoscopy to completion of intubation.

- Clinical duration of rocuronium blockade.

- Intubating conditions were assessed using Cooper's scoring system (Table 1 ).

Maintenance of anaesthesia with sevoflurane $1.5 \%$ to $2 \%$, $\mathrm{N}_{2} \mathrm{O}: \mathrm{O}_{2} @ 60: 40$. At the completion of surgery in all cases, neuromuscular blockade was reversed with $0.07 \mathrm{mg} / \mathrm{kg}$ of Neostigmine and Glycopyrrolate $20 \mathrm{ug} / \mathrm{kg}$ IV.

\section{Statistical Analysis \\ Data was analysed using the statistics software Vassarstats.com. Demographic data was analysed with Fisher's exact test. Continuous data like Heart rate and Blood pressure was analysed with One-Way ANOVA test within and between the groups. Intubating conditions according to Cooper's grading was analysed in percentage between the groups. Data was expressed as Mean \pm SD was calculated using Chi-square test. $\mathrm{P}<0.05$ was considered significant.}

\section{RESULTS}

75 patients were enrolled for this randomised, doubleblinded and single centred study. All the patients completed the study successfully. All patients of 3 groups were comparable regarding the demographic data like age, weight, ASA grading and duration of surgery as represented in Table2. The mean onset time to muscle relaxation was significantly less in the rocuronium priming (RR) group and rocuronium with magnesium (RM) group when compared to the control group, $\mathrm{p}<0.001$, statistically significant, represented in Table 3. Mean time taken for laryngoscopy and intubation was 
comparable between RR group (13 \pm 1.4 seconds) and RM group (14.5 \pm 1.25 seconds). In the control group (RC), the mean time taken to intubation was significantly higher $(19.5$ \pm 1.30 seconds) when compared to other two study groups with p-value of 0.000 , which is statistically significant, represented in Table 3. Mean intubation scores according to Cooper's grading were represented in Table 4 and Figure 1. They were comparable in three groups. Distribution of intubation scores in percentage according to Cooper's grading was represented in Table 5; 92\% (23) of cases in RR group reported excellent intubating conditions, 84\% (21) of cases in RM group reported excellent intubating conditions and only $40 \%$ (10) of cases in the control group reported excellent intubating conditions. None of the patients in three groups had fair or poor intubating conditions. Haemodynamic parameters like heart rate and SBP were significantly attenuated in the RM group at $1 \mathrm{~min}, 3 \mathrm{mins}$ and 5 mins following intubation when compared to RR group and control group as represented in Table 6 and Figure 2 and Figure 3. P-value $<0.001$, statistically highly significant.

\begin{tabular}{|c|c|c|c|c|}
\hline $\begin{array}{c}\text { Jaw } \\
\text { Relaxation }\end{array}$ & $\begin{array}{c}\text { Vocal } \\
\text { Cords }\end{array}$ & $\begin{array}{c}\text { Response to } \\
\text { Intubation }\end{array}$ & Score & $\begin{array}{c}\text { Intubating } \\
\text { Score } \\
\text { Grade }\end{array}$ \\
\hline Poor & Closed & $\begin{array}{c}\text { Severe coughing } \\
\text { or bucking }\end{array}$ & 0 & $0-2$ Poor \\
\hline Minimal & Closing & Mild coughing & 1 & 3-5 Fair \\
\hline Moderate & Moving & $\begin{array}{c}\text { Slight } \\
\text { diaphragmatic } \\
\text { movement }\end{array}$ & 2 & 6-7 Good \\
\hline Good & Open & None & 3 & 8-9 Excellent \\
\hline \multicolumn{5}{|c}{ Table 1. Cooper's Intubation Score } \\
\hline
\end{tabular}

\begin{tabular}{|c|c|c|c|c|}
\hline $\begin{array}{c}\text { Demographic } \\
\text { Variable }\end{array}$ & $\begin{array}{c}\text { Rocuronium } \\
\text { Priming } \\
\text { (RR) n= 25 }\end{array}$ & $\begin{array}{c}\text { Rocuronium } \\
\text { Magnesium } \\
\text { (RM) n= 25 }\end{array}$ & $\begin{array}{c}\text { Rocuronium } \\
\text { Control } \\
\text { (RC) n= 25 }\end{array}$ & $\begin{array}{c}\text { P } \\
\text { value }\end{array}$ \\
\hline Age in yrs. & $\begin{array}{c}49.91 \pm \\
10.66\end{array}$ & $\begin{array}{c}45.76 \pm \\
11.36\end{array}$ & $\begin{array}{c}48.30 \pm \\
10.8\end{array}$ & 0.166 \\
\hline Weight in kgs & $65.96 \pm 7.4$ & $59.96 \pm 7.4$ & $63.42 \pm 8.0$ & 0.418 \\
\hline Sex (M: F) & $15 / 10$ & $13 / 12$ & $11 / 4$ & \\
\hline $\begin{array}{c}\text { ASA grading } \\
\text { I/II }\end{array}$ & $20 / 5$ & $18 / 7$ & $22 / 3$ & \\
\hline $\begin{array}{c}\text { Duration of } \\
\text { Surgery in } \\
\text { minutes }\end{array}$ & $95 \pm 7.8$ & $96 \pm 9.6$ & $98 \pm 5.9$ & 0.399 \\
\hline \multicolumn{5}{|c|}{ Table 2. Demographic Data } \\
\hline
\end{tabular}

Data was expressed as Mean \pm SD, ratio and absolute numbers $\mathrm{p}>0.05$, statistically insignificant. Fisher's Exact test.

\begin{tabular}{|c|c|c|c|c|}
\hline Time & $\begin{array}{c}\text { Rocuronium } \\
\text { Priming } \\
\text { (RR) n= 25 }\end{array}$ & $\begin{array}{l}\text { Rocuronium } \\
\text { Magnesium } \\
\text { (RM) n= 25 }\end{array}$ & $\begin{array}{c}\text { Rocuronium } \\
\text { Control } \\
\text { (RC) n= 25 }\end{array}$ & P value \\
\hline $\begin{array}{c}\text { Onset time of } \\
\text { Rocuronium } \\
\text { (sec) }\end{array}$ & $61 \pm 1.0$ & $67.5 \pm 4.65$ & $96.5 \pm 6.44$ & $0.001^{*}$ \\
\hline $\begin{array}{c}\text { Time taken for } \\
\text { Laryngoscopy } \\
\text { and Intubation } \\
\text { (sec) }\end{array}$ & $13 \pm 1.41$ & $14.4 \pm 1.29$ & $15.60 \pm 1.4$ & 0.061 \\
\hline $\begin{array}{c}\text { Duration of } \\
\text { Rocuronium } \\
\text { Blockade } \\
\text { (mins) }\end{array}$ & $17.5 \pm 3.28$ & $26.5 \pm 3.97$ & $18.50 \pm 2.42$ & $0.002^{*}$ \\
\hline $\begin{array}{c}\text { Table 3. Onset Time of Rocuronium Blockade, Time taken } \\
\text { for intubation and duration of Rocuronium Blockade }\end{array}$ \\
\hline
\end{tabular}

Data expressed as Mean \pm SD. $^{x} \mathrm{p}<0.05$, statistically significant. ANOVA between groups.

\begin{tabular}{|c|c|c|c|}
\hline & $\begin{array}{c}\text { Rocuronium } \\
\text { Priming } \\
\text { (RR) n= 25 }\end{array}$ & $\begin{array}{c}\text { Rocuronium } \\
\text { Magnesium } \\
\text { (RM) n= 25 }\end{array}$ & $\begin{array}{c}\text { Rocuronium } \\
\text { Control } \\
\text { (RC) n= 25 }\end{array}$ \\
\hline Excellent & $23(96 \%)$ & $21(84 \%)$ & $10(40 \%)$ \\
\hline Good & $2(4 \%)$ & $4(16 \%)$ & $15(60 \%)$ \\
\hline Fair & nil & nil & Nil \\
\hline Poor & nil & nil & Nil \\
\hline \multicolumn{3}{|c|}{ Table 4. Distribution of Intubating conditions } \\
according to Cooper's Grading
\end{tabular}

Data expressed as percentage.

\begin{tabular}{|c|c|c|c|c|}
\hline & $\begin{array}{c}\text { Rocuronium } \\
\text { Priming } \\
\text { (RR) n= 25 }\end{array}$ & $\begin{array}{l}\text { Rocuronium } \\
\text { Magnesium } \\
\text { (RM) n= 25 }\end{array}$ & $\begin{array}{c}\text { Rocuronium } \\
\text { Control } \\
\text { (RC) n= 25 }\end{array}$ & $\begin{array}{c}\text { P } \\
\text { value }\end{array}$ \\
\hline $\begin{array}{c}\text { Mean } \\
\text { Intubation } \\
\text { Score }\end{array}$ & $8.73 \pm 0.46$ & $8.33 \pm 0.82$ & $7.86 \pm 0.49$ & 0.67 \\
\hline \multicolumn{3}{|c|}{ Table 5. Mean Intubation Score according to } \\
Cooper's Grading
\end{tabular}

Data expressed as mean \pm SD, p > 0.05, statistically insignificant.

\begin{tabular}{|c|c|c|c|c|}
\hline $\begin{array}{c}\text { Time in } \\
\text { Mins }\end{array}$ & $\begin{array}{c}\text { Rocuronium } \\
\text { Priming } \\
(\mathbf{R R}) \mathbf{n}=\mathbf{2 5}\end{array}$ & $\begin{array}{c}\text { Rocuronium } \\
\text { Magnesium } \\
(\mathbf{R M}) \mathbf{n}=\mathbf{2 5}\end{array}$ & $\begin{array}{c}\text { Rocuronium } \\
\text { Control } \\
(\mathbf{R C} \mathbf{n}=\mathbf{2 5}\end{array}$ & P value \\
\hline $\begin{array}{c}\text { HR at } \\
\text { Baseline }\end{array}$ & $75 \pm 9.52$ & $78.7 \pm 21.2$ & $74.5 \pm 9$ & 0.052 \\
\hline \begin{tabular}{c} 
HR at 1 min \\
\hline $\begin{array}{c}\text { HR at } 3 \\
\text { mins }\end{array}$
\end{tabular} & $112.8 \pm 8.65$ & $82 \pm 2.68$ & $118.9 \pm 7.14$ & $0.004^{*}$ \\
\hline $\begin{array}{c}\text { HR at } 5 \\
\text { mins }\end{array}$ & $99 \pm 3.65$ & $77.5 \pm 3.42$ & $102 \pm 9.09$ & $0.020^{*}$ \\
\hline $\begin{array}{c}\text { SBP at } \\
\text { Baseline }\end{array}$ & $125 \pm 8.16$ & $122.5 \pm 9.57$ & $124.5 \pm 8.56$ & 0.90 \\
\hline $\begin{array}{c}\text { SBP at } 1 \\
\text { min }\end{array}$ & $135 \pm 10.61$ & $118 \pm 4.16$ & $140 \pm 8.14$ & $0.019^{*}$ \\
\hline $\begin{array}{c}\text { SBP at } 3 \\
\text { mins }\end{array}$ & $125 \pm 4.75$ & $113.8 \pm 2.65$ & $128.2 \pm 3.86$ & $0.000^{*}$ \\
\hline $\begin{array}{c}\text { SBP at } 5 \\
\text { mins }\end{array}$ & $\begin{array}{c}122.7 \pm \\
10.35\end{array}$ & $110 \pm 6.73$ & $125 \pm 4.32$ & $0.002^{*}$ \\
\hline Table 6. Haemodynamic Parameters at different time \\
points after Intubation \\
\hline
\end{tabular}

Data expressed as mean $\pm \mathrm{SD},{ }^{*} \mathrm{p}<0.05$, statistically significant.

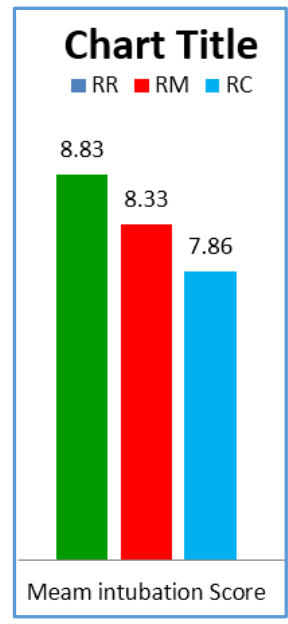

Figure 1. Mean Intubation Score 
RR: Rocuronium priming Group RM: Rocuronium with Magnesium Sulphate. RC: Rocuronium with Saline.

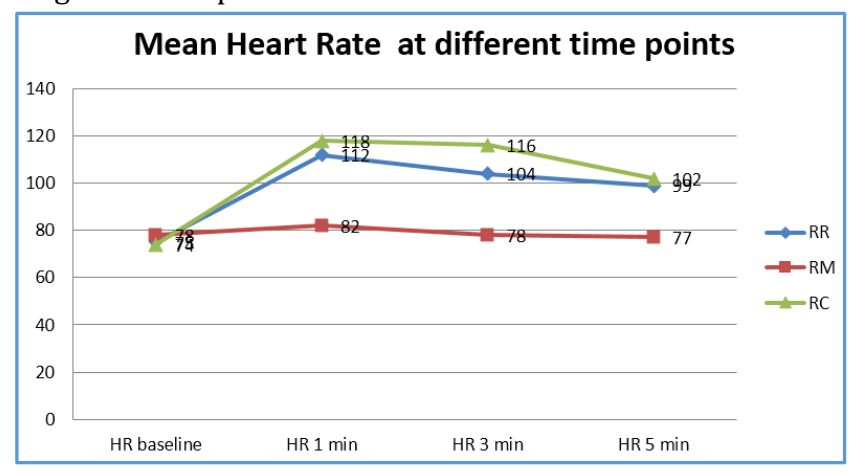

Figure 2. Mean Heart Rates

RR: Rocuronium priming Group RM: Rocuronium with Magnesium Sulphate. RC: Rocuronium with Saline.

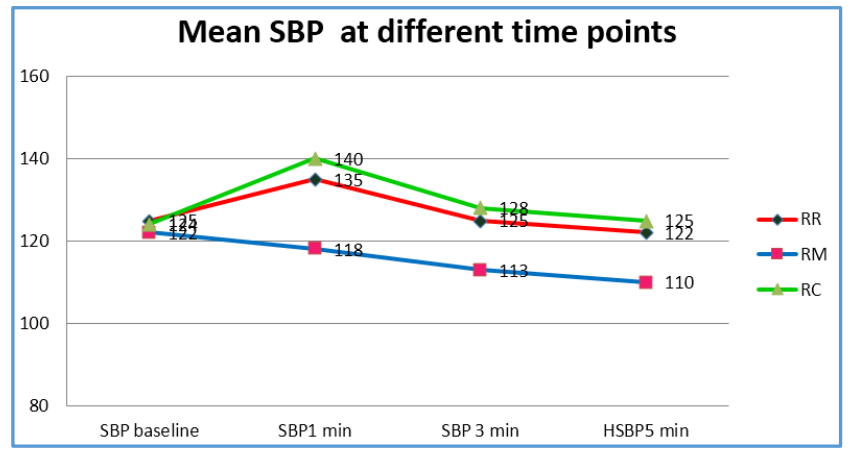

Figure 3. Mean Systolic Blood Pressure

RR: Rocuronium priming Group RM: Rocuronium with Magnesium Sulphate. RC: Rocuronium with Saline.

\section{DISCUSSION}

Rocuronium has evolved as an acceptable alternative when succinylcholine is contraindicated due to side effects like severe hyperkalaemia in burns patients, bradycardia with $2^{\text {nd }}$ dose of succinylcholine, disease or denervation of muscle membranes, conditions with increased intragastric, intraocular and intracranial pressures and also postoperative myalgias due to fasciculations or when there is absolute need for rapid sequence intubation or an anticipated difficult airway along with contraindications to succinylcholine.8,9 Rocuronium has proved to be successful agent after succinylcholine to produce rapid onset of neuromuscular blockade. However, according to various clinical trials, the time to achieve maximum neuromuscular blockade with $2 \mathrm{ED}_{95}$ dose of rocuronium is still lower than that of succinylcholine. ${ }^{10}$ This onset time can be accelerated by various pharmacological interventions or by increasing the dose of rocuronium. ${ }^{11}$ But increasing the dose of rocuronium can prolong the neuromuscular blockade. Hence, priming with sub-paralysing dose of rocuronium, pretreatment with magnesium sulphate, ephedrine, lignocaine etc.; have been used in various clinical trials with varying efficacies to accelerate the onset of rocuronium muscle blockade. 12

This study demonstrated that priming dose of rocuronium as well as pre-treatment with magnesium sulphate during rocuronium intubation comparably accelerated onset times of muscle relaxation and produced excellent-to-good intubating conditions. The control group differed significantly in the above outcomes with statistical significance.

M Hanumantha Rao et al conducted a clinical study and proved that priming with $10 \%$ of intubating dose of rocuronium 3 minutes prior to intubation accelerated the onset time to muscle relaxation when compared to rocuronium intubation without priming $(50.67 \pm 7.39$ vs. $94 \pm$ 11.62 seconds). ${ }^{13}$ However, the intubating conditions were excellent and comparable in both the groups without any adverse effects.

DS Shashank et al evaluated the effects of pre-treatment with different non-depolarising neuromuscular blockers (Rocuronium vs. vecuronium vs. atracurium) on the facilitation of intubation and concluded that pre-treatment with rocuronium facilitated endotracheal intubation within 60 seconds when compared to other agents; however, it cannot attenuate haemodynamic changes associated with laryngoscopy and intubation. ${ }^{14}$

Jing Dong, Lingqi Gao et al conducted a network metaanalysis on various pharmacological interventions for acceleration of the onset time of rocuronium and concluded that rocuronium priming, pre-treatment with ephedrine and pre-treatment with magnesium sulphate were all effective in accelerating the onset time of rocuronium with comparable efficacy. ${ }^{15}$ However, they reported that due to heterogeneity of studies, more strict clinical trials are needed to derive concrete conclusions. Nirmal Seshagiri et al studied the effect of magnesium sulphate pre-treatment in conjunction with rocuronium priming versus rocuronium priming alone and concluded that rocuronium priming along with magnesium sulphate accelerated the onset of neuromuscular blockade (73 vs. 85.2 seconds), improved rapid sequence intubating conditions and resulted in earlier endotracheal intubation when compared with rocuronium priming alone. ${ }^{16}$

Czarnetzki $\mathrm{C}$ et al analysed the time-course of rocuronium-induced neuromuscular block after pertreatment with magnesium sulphate and concluded that magnesium sulphate was given 15 minutes before propofol anaesthesia reduces the onset time of rocuronium by about $35 \%$ and prolongs the total recovery time by about $25 \% .{ }^{17}$

Laura Rodriguez-Rubio et al conducted a meta-analysis on the interaction between magnesium sulphate and neuromuscular blockers during the peri-operative period and concluded that the administration of magnesium sulphate during the peri-operative period alters neuromuscular blockade pharmacodynamics causing shortening of the onset time and prolongs the clinical duration and recovery times of these drugs. ${ }^{18}$ The results of the above studies correlated well with the observations of this study with respect to onset time of rocuronium blockade and intubating conditions according to Cooper's grading.

Though, all the above-mentioned studies reported acceleration in the onset time of rocuronium blockade, the percentage of reduction in onset time varied between studies owing to the heterogeneity of study design, i.e. differing doses of rocuronium, differing doses of magnesium sulphate, differences in the time of administration of drugs, differences in the study population and the sample size. In this study, $96 \%$ of patients in RR group and $84 \%$ of patients in RM group had excellent intubating conditions when compared to $40 \%$ 
of patients in the control group, which correlated with the above studies. Haemodynamic parameters like HR and SBP were significantly alleviated at $1 \mathrm{~min}, 3 \mathrm{mins}$ and $5 \mathrm{mins}$ in post-intubation in rocuronium with magnesium sulphate group when compared with RR group and RC groups, which has similarities with the observations of meta-analysis done by Seong-Joo Park et al, who analysed the effects of magnesium sulphate pre-treatment with rocuronium intubation under propofol and alfentanil anaesthesia. ${ }^{19}$ Our study differed from the above-mentioned studies in the dose of magnesium sulphate where they have used $50 \mathrm{mg} / \mathrm{kg}$ or 60 $\mathrm{mg} / \mathrm{kg}$ doses, whereas in this study the dose of magnesium sulphate is chosen to be $30 \mathrm{mg} / \mathrm{kg}$ IV in order to avoid delayed recovery from neuromuscular blockade. None of the patients in this study reported side effects to magnesium sulphate with the mentioned dose, as it was administered over 10 minutes slowly and diluted in $100 \mathrm{~mL}$ normal saline. Authors like Griffith $\mathrm{K}$ et al and Aziz L et al along with few other studies documented the side effects of priming dose of rocuronium like diplopia, ptosis, difficulty in breathing and difficulty in swallowing. ${ }^{20,21,22}$ These side effects can be alleviated with reduction in the priming dose of rocuronium to $1 / 10$ th dose of intubating dose strictly. In this study, the priming dose of rocuronium is one-tenth of the intubating dose.

None of the patients in this study reported side effects after priming dose of rocuronium, as they were adequately sedated with midazolam and fentanyl and pre-oxygenation was started at the same time of administering rocuronium (3 mins) to all the patients.

One of the main limitations of this study is limited sample size. Another limitation is neuromuscular monitoring which was not done for assessing the onset time and intubating conditions, as neuromuscular monitor was not available for all cases in our institution and assessment was solely done depending on the clinical neuromuscular blockade. Further clinical trials would be recommended to validate the optimal dose of magnesium sulphate for pre-treatment with rocuronium for intubation.

\section{Limitation}

Since the duration of the study was less, the sample size was taken for convenience.

\section{CONCLUSION}

- Interventions like rocuronium priming and/ or pretreatment with magnesium sulphate significantly accelerated the onset time to intubating dose of rocuronium when compared to control group.

- Rocuronium priming and pre-treatment with magnesium sulphate comparably produced good-toexcellent intubating conditions with rocuronium. Rocuronium intubation alone without priming also produced good-to-excellent intubating conditions, but more $(60 \%)$ percentage of patients had good intubating conditions than excellent intubating conditions (40\%). Mean intubation scores were comparable in all the three groups.

- Pre-treatment with magnesium sulphate caused significant attenuation of haemodynamics during the immediate period after intubation when compared to the other two groups.
- Clinical duration of neuromuscular blockade in the magnesium sulphate pre-treatment group has been slightly prolonged for only few minutes with the dose of $30 \mathrm{mg} / \mathrm{kg}$ used in this study without causing delayed recovery.

Hence, it can be safely recommended that priming with one-tenth dose of rocuronium 3 minutes prior to intubation or pre-treatment with magnesium sulphate $30 \mathrm{mg} / \mathrm{kg} 15$ minutes prior to intubation can cause significant acceleration in the onset time to muscle relaxation and optimal intubating conditions with regular $0.6 \mathrm{mg} / \mathrm{kg}$ dose of rocuronium for intubation without any side effects.

\section{REFERENCES}

[1] Magorian T, Flannery KB, Miller RD. Comparison of rocuronium, succinylcholine and vecuronium for rapid-sequence induction of anesthesia in adult patients. Anesthesiology 1993;79(5):913-8.

[2] Huizinga ACT, Vandenbrom RHG, Wierda JMKH, et al. Intubating conditions and onset of neuromuscular block of rocuronium (Org 9426): a comparison with suxamethonium. Acta Anaesthesiol Scand 1992;36(5):463-8.

[3] Sluga M, Ummenhofer W, Studer W, et al. Rocuronium versus succinylcholine for rapid sequence induction of anesthesia and endotracheal intubation: a prospective, randomized trial in emergent cases. Anesth Analg 2005;101(5):1356-61.

[4] Weiss JH, Gratz I, Goldberg ME, et al. Double-blind comparison of two doses of rocuronium and succinylcholine for rapid-sequence intubation. J Clin Anesth 1997;9(5):379-82.

[5] Fuchs-Buder T, Claudius C, Skovgaard LT, et al. Good clinical research practice in pharmacodynamic studies of neuromuscular blocking agents II: the Stockholm revision. Acta Anaesthesiol Scand 2007;51(7):789808.

[6] Yavascaoglu B, Cebelli V, Kelebek N, et al. Comparison of different priming techniques on the onset time and intubating conditions of rocuronium. Eur J Anaesthesiol 2002;19(7):517-21.

[7] Tran DTT, Newton EK, Mount VAH, et al. Rocuronium vs. succinylcholine for rapid sequence intubation: a Cochrane systematic review. Anesthesia 2017;72(6):765-77.

[8] Andrews JI, Kumar N., Van den Brom RHG, et al. A large simple randomized trial of rocuronium versus succiylcholine in rapid-sequence induction of anaesthesia along with propofol. Acta Anaesthesiol Scand 1999;43(1):4-8.

[9] Seupaul RA, Jones JH. Evidenve-based emergency medicine. Does succinylcholine maximize intubating conditions better than rocuronium for rapid sequence intubation? Ann Emerg Med 2011;57(3):301-2.

[10] El-Kobbia NM, Doghaim MM, Moustafa MA, et al. Comparative study between succinylcholine, rocuronium and magnesium sulphate with rocuronium in rapid sequence induction. Res Opin Anesth \& Intensive Care 2015;2(2):57-61. 
[11] Saiprabha S, Jithin TN. A comparative study of rocuronium priming, magnesium pre-treatment and their combination in neuromuscular blocking characteristics and quality of tracheal intubating conditions. Indian Journal of Applied Research 2017;7(11). | ISSN - 2249-555x | IF: 4.894 | IC value: 79.96

[12] Kumar M, Talwar N, Goyal R, et al. Effect of magnesium sulfate with propofol induction of anesthesia on succinylcholine-induced fasciculations and myalgia. J Anaesthesiol Clin Pharmacol 2012;28(1):81-5.

[13] Rao MH, Venkatraman A, Mallleswari R. Comparison of intubating conditions between rocuronium with priming and without priming: Randomized and double-blind study. Indian Journal of Anaesthesia 2011;55(5):494-8.

[14] Shashank DS, Singh NR, Singh LK. Effects of pretreatment with different neuromuscular blocking agents on facilitation of intubation with rocuronium: a prospective randomized comparative study. Indian Journal of Anaesthesia 2014;58(3):303-8.

[15] Dong J, Gao L, Lu W, et al. Pharmacological interventions for acceleration of the onset time of rocuronium: a meta-analysis. PLoS One 2014;9(12):e114231.

[16] Nirmal S, Khalid Z, Lokesh R, et al. The effect of magnesium sulphate pre-treatment on rocuronium priming in achieving rapid onset of intubating conditions. J Anesthesia \& Intensive Care Med 2018;6(4):555693.
[17] Czarnetzki C, Lysakowski C. Elia N. et al. Time course of rocuronium-induced neuromuscular block after pre-treatment with magnesium sulphate: a randomised study. Acta Anaesthesiol Scand 2010;54(3):299-306.

[18] Rodríguez-Rubio L, Pozo SGDJ, Nava E, et al. Interaction between magnesium sulfate and neuromuscular blockers during the perioperative period. A systematic review and meta-analysis. Journal of Clinical Anesthesia 2016;34:524-34.

[19] Park SJ, Cho YJ, Oh JH, et al. Pretreatment of magnesium sulphate improves intubating conditions of rapid sequence tracheal intubation using alfentanil, propofol and rocuronium - a randomized trial. Korean Journal of Anesthesiology 2013;65(3):221-7.

[20] Griffith KE, Joshi GP, Whitman PF, et al. Priming with rocuronium accelerates the onset of neuromuscular blockade. Journal of Clinical Anaesthesia 1997;9(3):204-7.

[21] Aziz L, Jahangir SM, Chandary SN, et al. The effect of priming with vecuronium and rocuronium on young and elderly patients. Anesth Analg 1997;85(3):663-6.

[22] Sridhar SK, Lagoo JY, Sathyanarayana PS. A comparative study to evaluate the effects of priming on intubating time and conditions with rocuronium bromide. Karnataka Anaesth J 2015;1(2):55-9. 